\title{
Sheep Management As a Deterrent to Predation
}

\author{
J. KENT MCADOO AND HUDSON A. GLIMP
}

$\mathrm{T}$ The predator control controversy of the 1970's resulted in several studies which documented losses of domestic sheep to predators (primarily coyotes) in the western states. Results of these studies indicate that the extent of coyote predation on sheep is variable from one operation to another, year to year, and season to season. Predation intensity is influenced by the methods and intensity of predator control, sheep management, availability of natural prey, and other factors.

A diversity of opinion exists as to the effectiveness of various predator control methods. Many ranchers think the use of compound 1080 (monosodium fluoroacetate) was effective in keeping coyote numbers down before its use was prohibited on public lands. Scientists disagree among themselves about the relative effectiveness of poisons, trapping, aerial hunting, "denning," and other methods. Criticism from environmentalists and others has resulted in greater consideration being given to the selectivity, specificity, environmental and human safety, and humaneness of various methods. The controversy

\section{Good sheep management can be just as important for protection of sheep herds as a predator control program.}

has resulted in research to test old and new predator control methods, as well as non-lethal methods of damage abatement (i.e., repellents, aversive conditioners, etc.). Federal and state agencies have been restricted in their use of certain control methods by government regulation and public sentiment. Meanwhile, predation has been cited as one of the economic factors blamed for the decline of the American sheep industry during the last three decades, with many ranchers having sold their operations. In Nevada, sheep numbers have decreased from 300,000 in 1972 to 80,000 in 1998.

We believe that most ranchers could alleviate much of their loss to predators by changing and/or implementing various sheep management techniques. The management suggestions discussed below are not new, and are being used by some ranchers already. Good sheep management can be just as important for protection of sheep herds as a predator control program. Obviously, when government predator control wanes or becomes unpredictable, sheep management becomes even more important. The suggestions that follow represent what we think are some examples of sound sheep management.

\section{Season of Lambing and Range-use Timing}

Shed lambing, as opposed to drop-band lambing on open range, provides a great deal of protection for newborn lambs from predation. In a typical shed-lambing operation, the ewes and lambs are kept in corrals adjacent to the lambing shed for up to two weeks after birth. Curtailed predation is not the only advantage of this system. Lamb crops of 150 to $200 \%$ are not uncommon under shed lambing conditions, as compared to 60 to $130 \%$ on the range. Many lambs and ewes that typically would be lost due to lambing complications in range lambing can be saved in sheds. Sick lambs can be nursed, orphaned lambs can be "mothered up" more easily, and the delicate ewe/lamb bond is less likely to be broken in shed lambing.

Shed lambing also provides the opportunity for lambing earlier in the season. With early lambing there is possibly a better market. More important to western operations is the possibility that, by lambing two months earlier, the intensive late summer predation of lambs by coyotes could be avoided. This late summer predation peak has been documented in several studies. During a study in northern Nevada, we observed that a sheep operation which neighbored our summer allotment had shipped their lambs just prior to the intensive late summer predation period we experienced. Communication with a government trapper and herders of this operation revealed that the lambs were born in sheds, about two months earlier than lambs of most ranchers in the area. The early lambs were therefore afforded protection from predators during both the critical lambing and late summer periods.

An alternative to using sheds to change the season of lambing is to move the sheep to a milder climate for late fall and winter lambing. Many producers in Idaho move their ewes to Arizona or southern California for lambing in December through February on alfalfa fields and crop residues. Although trucking expenses are high, these expenses are offset by reduced labor and feed costs and the lack of facilities costs for lambing sheds. The lambs are weaned upon return to Idaho in May, placed on high quality summer range, then sold at heavy weights in late July or early August. This system also avoids

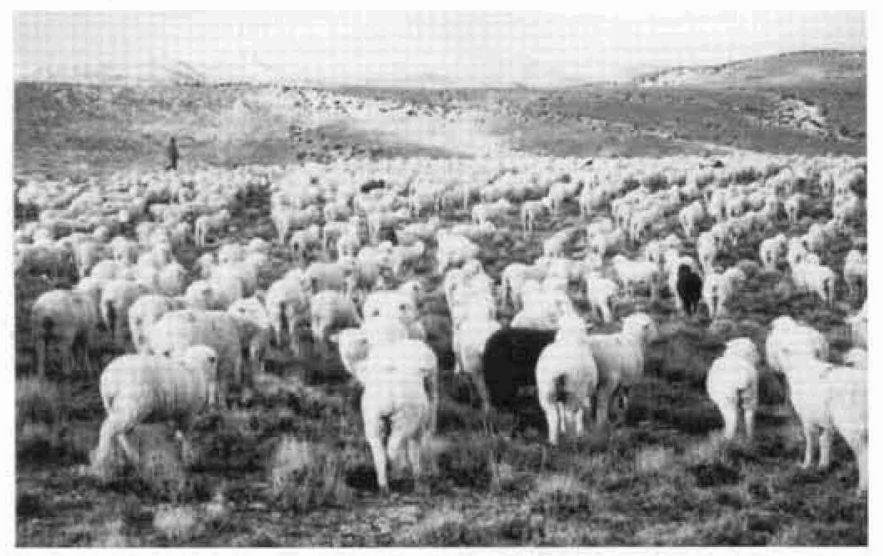

Open range herded sheep in northern Nevada. 
the late summer high predation period and the costs of shed lambing.

The primary disadvantage of shed lambing is cost. Depending on the availability and quality of lambing facilities, feed costs, labor resources, and the market price of lambs, shed lambing can cost as much as 0.3 to 0.5 lambs weaned per ewe. Studies by Walker et al. (1993) in Idaho and Burfening and Van Horn (1993) in Montana suggest that, with adequate predator control, shed lambing may increase the pounds of lamb weaned per ewe by no more than $20 \%$ over pasture or range lambing in the spring. These data suggest that shed lambing may be economically viable only when using prolific breeds (greater than $175 \%$ lamb crop expected), when pregnancy diagnosis determines that ewes are carrying twins, when lamb prices are substantially higher than today's prices, or when predation is known to be a problem that will result in the loss of over 0.2 to 0.5 lambs per ewe.

\section{Herders as Guardians}

Possibly the most effective and economically feasible method of curtailing predation is the simplest. Equipping herders with flat-shooting scoped rifles and training them in the proper use and maintenance of such equipment could be the best protection a rancher could give his sheep. We have seen several coyotes shot at and missed or, even worse, wounded by herders. Most of these instances were the results of using either: (1) an unfamiliar or unsighted firearm; (2) a low velocity caliber; or (3) an improperly maintained weapon. We have also accompanied herders who approached their sheep unarmed as coyotes moved within easy rifle range.

Coyotes observed near the sheep by herders are frequently problem animals (as evidenced by fresh kills found immediate- ly prior to or just after predator observation). If herders were able to kill even 50 percent of these coyotes sighted within rifle range, we believe losses would be significantly curtailed. The elimination of one problem animal by a herder could be of more help than the trapping of several others at random.

Each herder's job description should include the following directives: (1) to approach their sheep well before dawn (when most kills occur); (2) to carry a rifle at all times when enroute to or from sheep; and (3) to keep this rifle sighted in, wellcleaned, and lubricated. Monetarily rewarding herders for each coyote shot would provide added incentive. Herders could also be provided with traps and encouraged to harvest more coyotes in this manner. However, this would probably not be as effective as shooting coyotes seen near sheep. Obviously, all state and federal regulations pertaining to the harvest of predators should be followed.

\section{Bedding Sheep Near Camp}

Generally speaking, herding of sheep on public lands in the West has changed very little in the last century. However, before the establishment of regulations governing the use of public lands by livestock, sheep were kept under closer surveillance than they are now. Specifically, herders' camps were kept closer to the sheep bands. The sheep grazed daily from a common bedding ground to which they returned each night, and the herders' camp was put at this location. This camp and the sheep bed ground were not moved until all the easily accessible range had been grazed. Although this system probably discouraged many predator attacks, the trampling effect on bed areas and over-use of surrounding range was often severe. Therefore, rules were instituted requiring that the sheep not bed in the same area night after night.

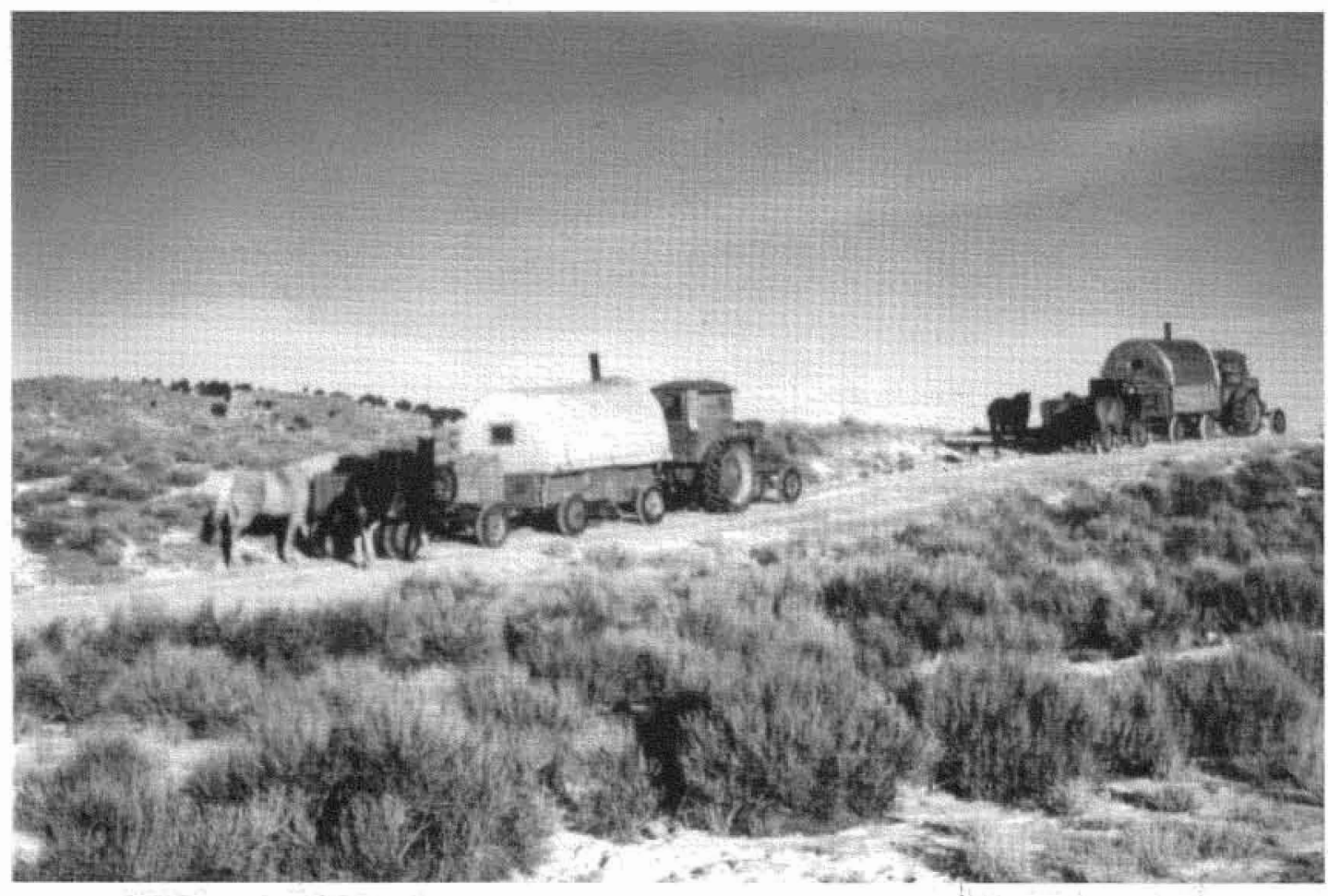

Moving herders' camps often to stay close to sheep bedding grounds can reduce predation. 


\section{SHEEP MANAGEMENT SUGGESTIONS FOR REDUCING PREDATION}

Adjust Lambing Season and Range-Use Timing

Train and Equip Herders as Guardians

Instruct Herders to Bed Sheep Near Camp

Avoid Perennial Problem Areas

Use Guardian Dogs

Under the present system, the sheep are bedded down in a different place every night. However, the tradition of a semistationary camp has remained, and therefore the sheep are bedded successively farther away from camp until it is considered worthwhile to move camp closer. A range-use problem has been alleviated, but a predation problem has been intensified.

A "hybrid" of the old and new methods could produce desirable results both for range conservation and predation avoidance. If camp were moved daily (or at least every other day) to each new bed area for the sheep, both problems could be reduced. Towne and Wentworth (1945) state that the old method of bedding sheep at herders' camps discouraged the approach of predators. Similarly, where sheep are kept immediately adjacent to a farm dwelling, only the bolder coyotes attempt attacks on sheep. The mere presence (scent) of man and his equipment near the sheep is probably enough to ward off all but the hungriest and/or boldest of predators. In addition, the presence of sheepdog(s) around camp might also be a deterrent. McAdoo and Klebenow (1978) found that predation by coyotes is most severe when sheep become scattered in bunches at night, with those bunches farthest from the herder's camp being more vulnerable to predation.

Moving camps more often entails additional work for herders and camp tenders. However, the amount of work involved could be decreased with advanced planning. Ranchers know from experience the areas and/or time periods when the most intensive predation occurs. Ranchers could advise their herders to move camp frequently only in certain areas and during problem time periods.

If the herders are living in sheep wagons rather than in tents, an alternative to moving the wagon each day exists. Herders could use the wagon as "base camp" and sleep in a small tent near the sheep when protection is necessary. This practice is already being implemented in some areas.

Trucking sheep rather than trailing them would alleviate the spotty, but often severe predator losses incurred between seasonal ranges. Although trucking is expensive, studies have shown that the value of weight loss in sheep over long trail routes may be greater than the cost of hauling. Trucking sheep could also reduce the number of sheep lost as strays and reduce losses to halogeton poisoning. Trail routes in many areas of the West are infested with this plant, and losses of up to 1,000 sheep in just a few days have been documented. Many ranchers have already made the change from trailing to trucking.

\section{Avoiding Problem Areas}

Predation can be reduced simply by avoiding problem areas within a range allotment. During a study in eastern Nevada we observed that each time sheep were moved into a certain drainage on a large winter allotment, predation occurred. When the sheep were moved out, predation ceased, and when they were moved in again, predation started. In this particular instance, moving the sheep one-half mile was all that was necessary to avoid the problem. If plenty of forage is available elsewhere, we suggest that perennial problem areas be avoided.

\section{Guardian Dogs}

The use of guardian dogs is not new, with many historic references to their use in Europe and Asia. There is evidence that guardian dogs may have been used in the western and southwestern U.S. in the 19th century, but this use was discontinued due to the elimination of predators and/or the implementation of other predator control methods. Several Old World breeds of guardian dogs have been introduced into the U.S. since the 1960's, and these animals are increasingly being used in western range sheep operations.

The primary benefits of guardian dogs are reduced predation costs and reductions in labor and other costs associated with

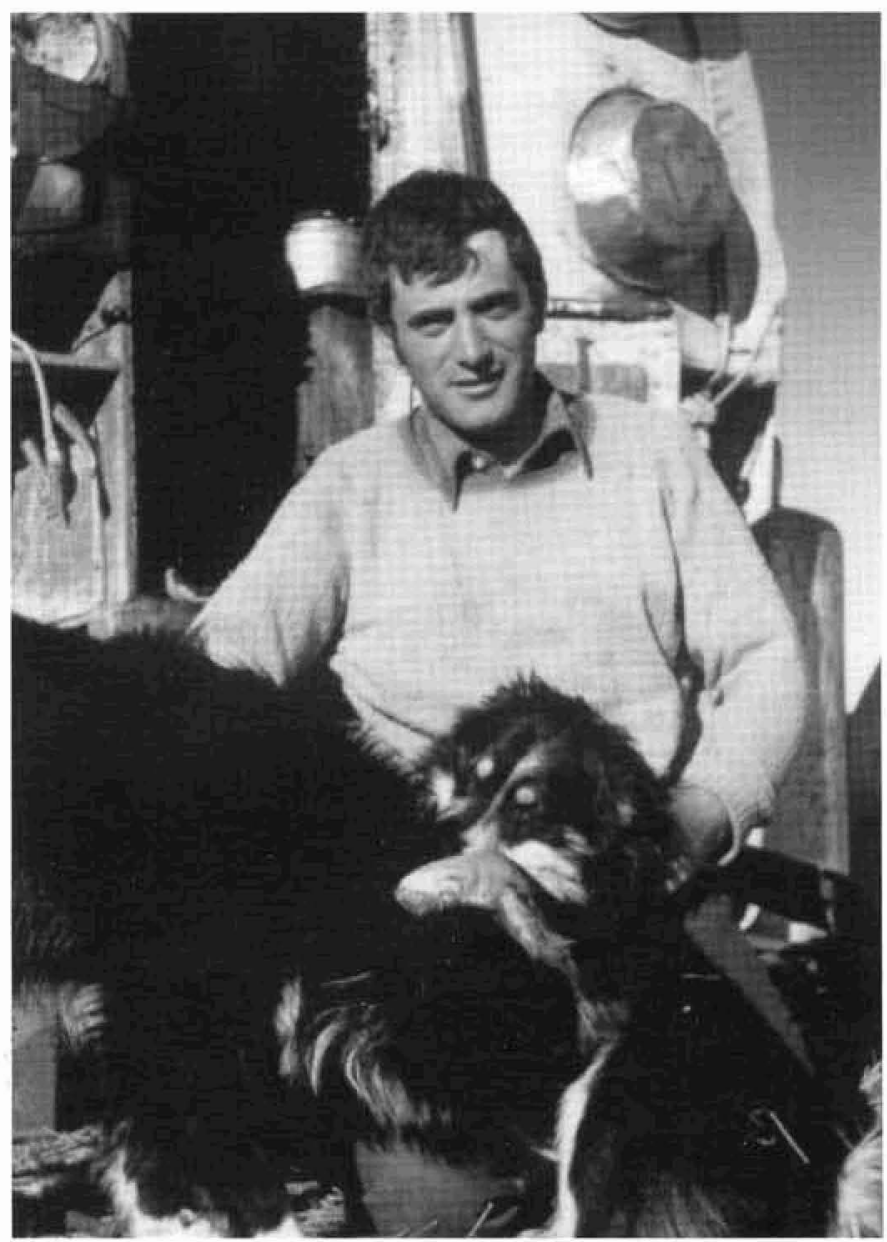

The presence of a herder and his dog close to sheep reduces predation. 
alternative predator control methods. Disadvantages include cost of purchase and training guardian dogs, variations in success rate that may be influenced by several factors, and the care and maintenance costs associated with these dogs.

Many western range sheep producers could not remain in business without the use of guardian dogs. They should be considered as a potentially valuable tool in the arsenal of management practices recommended for consideration in this paper. Although guardian dogs will kill invading coyotes and wild or stray dogs, their primary function is intimidation that keeps predators away from the flock. The intimidation factor is also of benefit, but to a lesser extent, in protecting flocks against larger predators such as mountain lions and bears.

\section{Other Management Techniques}

Other management practices have been used with varying success, depending on site-specific variables. These practices include: scare tactics such as lights, bells, sirens, intermittent radio noise, cannons, and other explosive devices; toxic collars; aversive agents or repellents; electric fencing; and other guardian animals such as donkeys and llamas. This paper does not discuss conventional predator control methods (such as traps, snares, M-44 cyanide devices, denning, aerial hunting, and the use of hunting dogs) available through federal or state agencies and commercially licensed hunters or trappers.

Producers are encouraged to use all legal and economically viable methods available to them for predator control. Working with state sheep associations, and in some states wildlife organizations where predation on wildlife is a serious problem, is recommended. If public lands are used, the producer must also be aware of the regulations for predator control on these lands.

\section{Conclusion}

Our experience with sheep operations has made us aware that the application of all the techniques described above would not be feasible for every sheep operation. However, we believe that most operations could employ one or more of these or other management practices which would discourage predation. The conflict between predator and man will always exist. With a crafty and resilient animal like the coyote, no one method of control or management will ever be the cureall. But we believe that improved sheep management is a good starting place. Any economical management techniques that might reduce predation should be considered.

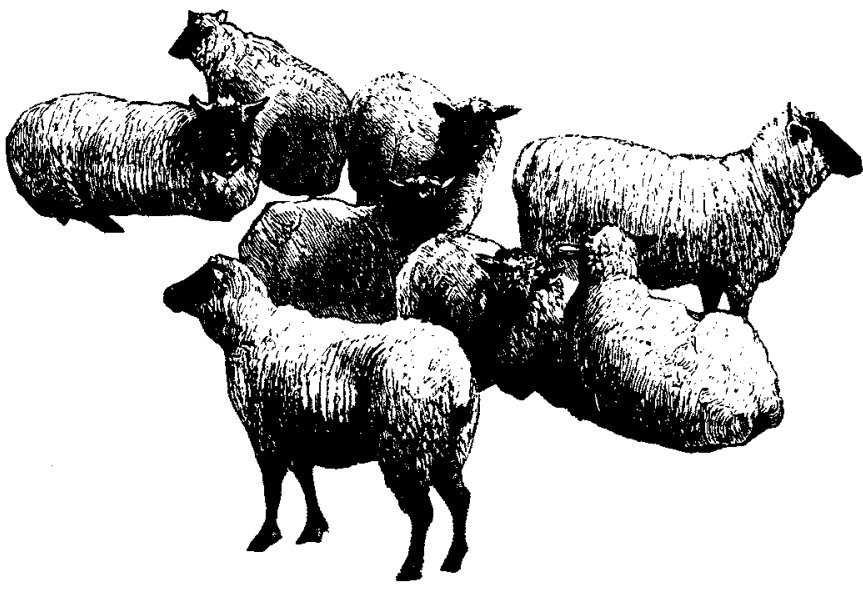

\section{Suggested Reading}

American Sheep Ind. Assoc. 1997. Sheepman's production handbook. Englewood, Colo.

Burfening, P.J., and J.L. Van Horn. 1993. Comparison of range versus shed lambing in the northern Great Plains. Sheep Res. J. 9:66.

Green, J.S., and R.A. Woodruff. 1990. Livestock guarding dogs: protecting sheep from predators. U.S. Dept. Agric. Bull.

Klebenow, D.A., and J.K. McAdoo. 1976. Predation on domestic sheep in northeastern Nevada. J. Range Manage. 29:96-100.

Klebenow, D.A., J. K. McAdoo, and J.D. Kauffeld. 1978. Predation on range sheep as related to predator control and sheep management. Proc. First International Rangeland Congress 1:270272.

McAdoo, J.K., and D.A. Klebenow. 1978. Predation on range sheep with no predator control. J. Range Manage. 31:111-114.

Towne, C.W., and E.M. Wentworth. 1945. Shepherd's Empire, Univ. of Oklahoma Press, Norman, Okla.

Walker, J.W., H.A. Glimp, S.L. Kronberg, and T.R. Kellom. 1993. When less may mean more: studies on range versus shed lambing in a cold desert shrub ecosystem. Professional Anim. Sci. $9: 153$.

Authors are rangeland resources specialist, University of Nevada Cooperative Extension, Northeast Extension Area, Elko, Nevada 89801; and State Sheep Specialist, University of Nevada Cooperative Extension, Reno, Nevada 89557. 